\title{
FUNCTIONAL DISABILITY AND ASSOCIATED CHRONIC CONDITIONS AMONG GERIATRIC POPULATIONS IN A RURAL COMMUNITY OF INDIA
}

\author{
D. CHAKRABARTY, P. K. MANDAL, N. MANNA, S. MALLIK, P. GHOSH, C. CHATTERJEE \\ J. C. SARDAR, M. SAU and A. K. SINHA ROY \\ Department of Community Medicine, Medical College, 88 College Street, Kolkata 700073, West Bengal, India
}

Corresponding Author: Dr. Pankaj K. Mandal

Email:drpankajkumarmandal@gmail.com

Conflict of Interest: None declared

\begin{abstract}
SUMMARY
Background: Geriatric population and chronic diseases are increasing throughout the world especially in developing countries like India. Because of social change and urbanization, disability is also a problem in India. As the major reasons for geriatric disabilities are chronic diseases, a study was undertaken.

Objectives: To find out the prevalence of different chronic diseases and disability among the geriatric population in a rural community of India and to determine the association between chronic diseases and disability of the geriatric population.

Method: A cross-sectional, observational community based study was conducted in a rural area of West Bengal, India through house to house visit for Clinical examination, observation and interview with a predesigned pre-tested proforma

Results: Out of 495 study population, 80 (16.16\%) were found to be functionally disabled as per ADL scale and more than half $(56.2 \%)$ of them had 3 or more chronic conditions. $92.5 \%$ of study populations had one or more chronic conditions

Conclusion: Association between different risk factors and disability was found with age, sex, anaemia, Chronic Obstructive Pulmonary Diseases(C.O.P.D), scabies, hypertrophy of prostate, ischaemic heart disease, osteoporosis, osteoarthritis and acid peptic disorder were the risk factors of disability. These data suggest the significant chronic conditions and risk factors associated with disability. Measures to reduce such chronic conditions and impairment would be the useful approach for the prevention of disability.
\end{abstract}

Keywords: disability, geriatric population, chronic condition, ADL scale, rural area

\section{INTRODUCTION}

The World is aging and so is its population. Increasing awareness, better health care, improved living conditions lead to increase life expectancy and geriatric population. By 2025, the number of elderly people is expected to rise more than 1.2 billion with about 840 million of these in low- income countries. ${ }^{1}$ In India, according to the Sample Registration System (2005) 7.2 percent of the total populations were above the age of 60 years $^{2}$.

Aging is a natural process and with the process of aging most organs decline in function resulting increase in chronic illness and disability. As the numbers of older and disabled persons grew and the prevalence of chronic disease increased, the importance of function in health and illness was recognized. ${ }^{3}$ Chronic illness and functional ability have an influence on the quality of life in elderly populations. There is also evidence that older people have the risk of multiple co-morbidities, ${ }^{4}$ which may lead to increased disability among them.

Disability could be prevented either by preventing the disease or by preventing the impairment. As the chronic conditions are the major causes of disability, assessment of chronic diseases and its association with disability will help in implementation of different preventive programmes and reduce the burden of the nation. This study was undertaken to determine the prevalence of different chronic diseases and disability; and the association between chronic diseases and disability among the geriatric population in a rural community of India.

\section{METHODS}

A community based cross-sectional study was carried out in the Tarakeswar block, at Hooghly district, West Bengal, the rural field practice area of Medical College Kolkata, India in the year 2007. Tarakeswar is situated around $50 \mathrm{Km}$ from Kolkata covering a population of 175,523. Considering the prevalence of chronic diseases among geriatric people as $45 \%{ }^{5}$ in rural areas, $95 \%$ confidence limit and allowable error $10 \%$, the 
sample size was calculated using Epi Info version 3.5.1 and it became 454 .

Adding 10\% non- response, the total number came out to be 500 . Aged 60 years or more was considered as geriatric population in India. The list of all persons aged 60 years or more was prepared from the voter list and it was 13,516. By using simple random sampling technique, total number of sample (500) was selected from the voter list with name and address. After taking verbal consent, geriatric people were interviewed by house-to-house visit, using a pre designed semistructured proforma.

First part of the proforma included socio-demographic and personal characteristics like age, sex, level of education, per capita income, religion and mother tongue. Second part of proforma contained questions about morbidity and disability. Morbidity was assessed by clinical examination and verified by the records, if available. Cured morbidity was excluded from the study.

Diseases were coded according to ICD-10. Later it was grouped under different system related diseases. Disability was ascertained by self reporting in performing ten non-instrumental activities of daily living (ADL) ${ }^{6}$. Based on ADL score the individuals were divided into two groups - (a) score $>10-$ Independent/functionally not disabled, (b) score $\leq 10-$ dependent/functionally disabled. Association between different risk factors and disability were assessed by binary logistic regression model. Data were analysed using Epi Info version 3.5.1 and SPSS version 14.

\section{RESULTS}

Due to incompleteness of proforma and non- response, ultimately final sample came to 495. Data of 495 samples were analysed. Table I shows the basic characteristic of sample and disabled population. Mean age and SD of the study population was $66.89 \pm 7.38$ years; $77.5 \%$ of disabled population was female.

Most of the population were Hindu by religion (96.4\%) and Bengali speaking (90.9\%). $88.8 \%$ of disabled populations were illiterate, $22.4 \%$ were living alone and $51.3 \%$ belonged to socio-economic class - IV \& V. More than half $(56.2 \%)$ of the disabled population had 3 or more chronic diseases and $7.5 \%$ of study population did not have any chronic condition. Prevalence of disability was $16.16 \%$ as per ADL scale.

Among the disabled population, $67.5 \%$ had the involvement of musculoskeletal system, followed by
Diseases of circulating system (43.8\%), Diseases of eye \& adnexae (33.8\%), Diseases of blood and blood forming organs $(22.5 \%)$ and Endocrine, nutritional and metabolic disorder $(22.5 \%)$.

Table 1 Basic Characteristic of the Sample

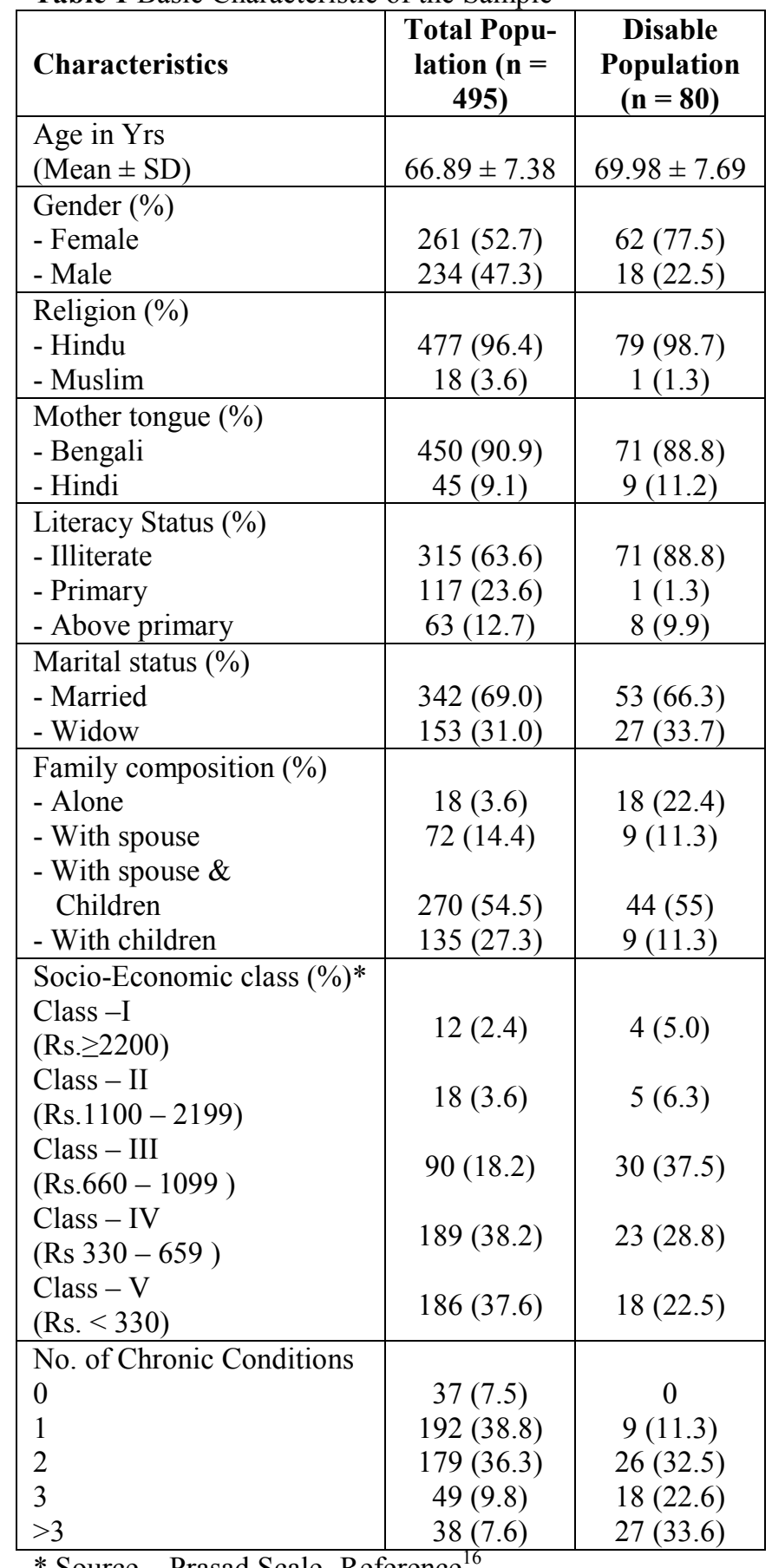

* Source - Prasad Scale- Reference ${ }^{16}$ 
Table 2 Overall Percentage of System wise Chronic Diseases by Level of Disability

\begin{tabular}{|l|c|c|c|}
\hline System Involved & $\begin{array}{c}\text { Not Disabled } \\
(\mathbf{n = 4 1 5 )} \\
(\text { ADL score } \mathbf{~ 1 0 )}\end{array}$ & $\begin{array}{c}\text { Disabled } \\
(\mathbf{n}=\mathbf{8 0}) \\
(\text { ADL score } \leq \mathbf{1 0})\end{array}$ & $\begin{array}{c}\mathbf{p} \\
\text { value }\end{array}$ \\
\hline Diseases of blood and blood forming organ & 10.8 & 22.5 & 0.007 \\
\hline Endocrine, nutritional and metabolic disorders & 8.7 & 22.5 & 0.000 \\
\hline Mental and behavioural disorders & 3.1 & 21.3 & 0.000 \\
\hline Diseases of nervous systems & 11.8 & 7.5 & 0.354 \\
\hline Diseases of eye and adnexae & 43.4 & 33.8 & 0.145 \\
\hline Diseases of ear and mastoid & 10.8 & 11.3 & 0.923 \\
\hline Diseases of circulating system & 21.9 & 43.8 & 0.000 \\
\hline Diseases of respiratory system & 21.7 & 11.3 & 0.047 \\
\hline Diseases of digestive system & 71.6 & 67.5 & 0.549 \\
\hline Diseases of skin and subcutaneous tissue & 12.8 & 1.3 & 0.004 \\
\hline Diseases of musculoskeletal system & 36.6 & 66.3 & 0.000 \\
\hline Diseases of genitourinary system & 10.8 & 5.0 & 0.162 \\
\hline
\end{tabular}

Diseases of blood and blood forming organs, Endocrine, nutritional and metabolic disorders, Mental and behavioural disorders, Diseases of circulatory system, Diseases of respiratory system, Diseases of skin and subcutaneous tissue, Diseases of musculoskeletal system were significantly higher among the disabled population in comparison to nondisabled population.

Table 3 Associations between the Presence of Chronic Diseases and Functional Disability in activities of Daily Living $(n=495)$

\begin{tabular}{|c|c|c|c|c|}
\hline $\begin{array}{l}\text { Chronic Disease } \\
\text { (ICD - 10 Code) }\end{array}$ & OR* $(95 \%$ CI $)$ & $\begin{array}{l}\text { Ra } \\
\text { nk }\end{array}$ & OR ** $(95 \%$ CI $)$ & Rank \\
\hline Anaemia (D50 D53) & $4.00(1.70-9.19)$ & 2 & $3.42(1.48-7.93)$ & 2 \\
\hline Cataract $(\mathrm{H} 25 \mathrm{H} 26)$ & $1.12(0.61-2.04)$ & 11 & $0.88(0.52-1.49)$ & 11 \\
\hline Deafness (H90 H91) & $1.04(0.42-2.55)$ & 12 & $0.72(0.29-1.74)$ & 12 \\
\hline C.O.P.D (J44 J45) & $0.70(0.34-1.46)$ & 14 & $0.50(0.24-1.03)$ & 14 \\
\hline Tuberculosis (A15 A18) & $1.53(0.60-3.89)$ & 9 & $2.04(0.72-5.72)$ & 6 \\
\hline Depression (F32 F33 F34) & $0.30(0.11-0.79)$ & 15 & $0.25(0.09-0.63)$ & 15 \\
\hline Dental Carries (K02) & $1.18(0.67-2.07)$ & 10 & $0.98(0.53-1.79)$ & 10 \\
\hline Scabies (B86) & $0.14(0.01-1.07)$ & 16 & $0.09(0.01-0.75)$ & 16 \\
\hline Osteoarthritis (M13) & $3.82(1.97-7.41)$ & 3 & $2.50(1.26-4.93)$ & 4 \\
\hline Prostate (N40) & $0.88(0.25-2.99)$ & 13 & $0.55(0.19-1.56)$ & 13 \\
\hline Diabetes (E11, E12) & $3.53(1.39-9.00)$ & 4 & $2.32(1.07-5.06)$ & 5 \\
\hline Neuropathy $(\mathrm{G} 35, \mathrm{G} 37)$ & $1.98(0.55-7.12)$ & 8 & $1.65(0.45-5.96)$ & 7 \\
\hline Hypertension (I10, I11, I15) & $2.42(1.08-5.44)$ & 6 & $1.46(0.70-3.03)$ & 9 \\
\hline I.H.D. (I20, I25, I27) & $2.26(0.93-5.52)$ & 7 & $1.52(0.67-3.48)$ & 8 \\
\hline Acid-Peptic Disorder (K25 K26 K27 K29 K30) & $3.15(1.66-5.97)$ & 5 & $2.99(1.60-5.57)$ & 3 \\
\hline Osteoporosis (M80, M82) & $7.97(3.72-17.0)$ & 1 & $7.81(3.94-15.4)$ & 1 \\
\hline
\end{tabular}

Note: $\mathrm{OR}=$ odds ratio; $\mathrm{CI}=$ confidence interval.

*OR adjusted for age and gender. ${ }^{* *} \mathrm{OR}$ additionally adjusted for the remaining chronic conditions.

Table 3 reveals the association between chronic diseases (ICD - 10) and functional disability among study population as estimated by odds ratio (ORs).

Conditions were ranked according to the magnitude of the association. Osteoporosis, Anaemia, Acid peptic disorder, Osteoarthritis and Diabetes were strongly associated with disability. Other diseases, associated with disability were Tuberculosis, Neuropathy, IHD and, Hypertension.
Association between different risk factors and disability by binary logistic regression analysis (Table 4) showed that age, sex, anaemia, C.O.P.D, Scabies, Hypertrophy of prostate, Ischemic Heart Disease, Osteoporosis, Osteoarthritis and Acid peptic disorder were the risk factors of disability. About fifty eight percent $(58.2 \%)$ of the disabilities were explained by these factors. 
Table 4 Association between disability and risk factors by binary logistic regression analysis

\begin{tabular}{|l|c|c|c|c|c|c|}
\hline Predictor Variable & B & S.E. & Wald & df & p value & Exp (B) \\
\hline Age & -.079 & .026 & 9.043 & 1 & .003 & .924 \\
\hline Sex & -1.575 & .499 & 9.978 & 1 & .002 & .207 \\
\hline Anaemia & 1.858 & .675 & 7.587 & 1 & .006 & 6.414 \\
\hline Cataract & -.325 & .417 & .609 & 1 & .435 & .722 \\
\hline Deafness & -.818 & .708 & 1.334 & 1 & .248 & .441 \\
\hline C.O.P.D & 1.258 & .495 & 6.457 & 1 & .011 & 3.517 \\
\hline Tuberculosis & 1.179 & .713 & 2.735 & 1 & .098 & 3.253 \\
\hline Depression & -.986 & .568 & 3.013 & 1 & .083 & .373 \\
\hline Dental caries & -.933 & .527 & 3.126 & 1 & .077 & .394 \\
\hline Scabies & -2.955 & 1.187 & 6.192 & 1 & .013 & .052 \\
\hline Osteoarthritis & .816 & .467 & 3.051 & 1 & .049 & 2.262 \\
\hline Prostate hypertrophy & -3.294 & .889 & 13.731 & 1 & .000 & .037 \\
\hline Diabetes & -.172 & .626 & .075 & 1 & .784 & .842 \\
\hline Neuropathy & -.947 & .736 & 1.653 & 1 & .199 & .388 \\
\hline Hypertension & -.011 & .384 & .001 & 1 & .978 & .989 \\
\hline Ischemic heart disease & 1.546 & .521 & 8.811 & 1 & .003 & 4.692 \\
\hline Acid peptic disorder & 1.719 & .482 & 12.711 & 1 & .000 & 5.579 \\
\hline Osteoporosis & 3.876 & .537 & 52.042 & 1 & .000 & 48.23 \\
\hline Constant & 6.913 & 4.819 & 2.058 & 1 & .151 & 1005.12 \\
\hline
\end{tabular}

\section{DISCUSSION}

Of the study population $92.5 \%$ had one or more chronic conditions, consistent with $89 \%$ among Kashmiri people in India ${ }^{7}$ and $88.9 \%$ in northern India whereas in different studies in the United States the prevalence varied from $82 \%$ to $88 \%{ }^{9,10}$ But among rural people of Chandigarh-India, the prevalence of morbidity was $77.6 \%{ }^{11}$ This wide variation of prevalence of morbidity may be due to the differences in the racial and ethnic origin of the study populations, socioeconomic status, criteria for considering older people and the questionnaires used.

In our study, musculoskeletal system disorder was the most prevalent morbidity among the disabled population, similar to the study conducted at four US clinics, Winston-Salem, NC, Hagerstown, MD, Pittsburgh, PA, and Sacramento, CA. ${ }^{12}$ The reason may be that when the people become older, there is deterioration of function of musculoskeletal system leading to restricted mobility, which adversely affects the older people to sustain independently in the society.

The present study observed that Osteoporosis, Anaemia, Acid peptic disorder, Osteoarthritis, Diabetes, Tuberculosis, Neuropathy, IHD and Hypertension were associated with disability. In a cross-sectional survey of the entire population aged 70 and over, living in Ospitaletto Brescia, northern Italy similar association with anaemia, diabetes, hypertension and heart disease was reported. ${ }^{13}$

In another longitudinal study among older Americans, association of heart disease, diabetes and arthritis with disability was observed. ${ }^{14}$ Joshi et al, in a crosssectional study at rural and urban area of Chandigarh (India), found that morbidities like asthma, COPD, hypertension, osteoarthritis, gastrointestinal disorders, anaemia, and eye and neurological problems were significantly associated with disability. ${ }^{8}$

In a study among African Americans association between hypertension and disability was also seen. ${ }^{15}$ This may be due to fact that morbidity and disability can differ from country to country and also in different places with in the country due to different ethnic factors, educational status, life style, nature of work \& working conditions of the study population and availability and utilization of health care services.

In our study an attempt has been made to find out the association between different risk factors with disability by binary logistic regression analysis. The study revealed that age, sex, osteoarthritis, anaemia, C.O.P.D, scabies, prostate hypertrophy, I.H.D, osteoporosis and acid peptic disorder were significantly associated as risk factors with disability and $58.2 \%$ of the disabilities were explained by these factors. 
In this regards, studies showing association of chronic conditions with disability by this regression model are scarce in Indian context.

\section{CONCLUSION}

As this was a descriptive study, the factors found as associated with disability could be suggestive, not a causal one. A little over half (58.2\%) of the risk factors of disability were explained by the present study. There may be other factors for disability, which were not identified in this study. Future analytical study with large sample would be conclusive for causal factors of disability.

However, the study highlighted that the different chronic conditions like osteoporosis, anaemia, C.O.P.D, scabies, prostate hypertrophy, I.H.D, osteoarthritis, acid peptic disorder, age and sex were significantly associated with functional disability of the geriatric population.

These analysis emphasized allocation of society's financial resources for the future programme of the geriatric population focusing preventive measures at the early stage and adequate treatment of such chronic diseases for their betterment and improving quality of life. National programmes and policies on prevention of these chronic conditions and risk factors among the geriatric population should be prioritized.

\section{REFERENCES}

1. Park K. Park's text book of preventive \& Social Medicine, K Park. Banarasidas Bhanot publishers, Jabalpur, India. $19^{\text {th }}$ edition.2007; 475

2. Sample Registration System Statistical Report. Government of India. Office of the register general India, New Delhi 2006; 1: 91

3. Katz S. and Stroud M.W. Functional assessment in geriatrics: A review of progress and directions. J Am Geriatr Soc 1989; 37: 267-271

4. Gijsen R, Hoeymans N, Schellevis FG, Ruwaard D, Satariano WA, van den Bos GA: Causes and consequences of comorbidity: a review. J Clin Epidemiol 2001; 54:661-674

5. Gupta Indrani, Dasgupta P., Sawhney M.. Health of the Elderly in India - some aspects of vulnerability, Inst. of economic Growth, University Enclave Delhi, India 2000: 4-28.

6. Handbook on health care of the elderly, a manual for physicians for primary and secondary health care facilities, WHO, Ministry of Health \& Family Welfare, Govt. of India 65-66

7. Parray SH, Ahmed D, Ahmed M, Gaash B, Morbidity Profile of Geriatric Population in Kashmir (India), Indian Journal for the Practising Doctor. 2008;4(6):1-2

8. Joshi K, Kumar R, Avasthi A. Morbidity profile and its relationship with disability and psychological distress among elderly people in Northern India. Int J Epidemiol 2003;32:978-987

9. Hoffman C, Rice D, Sung HY, Persons with chronic conditions. Their prevalence and costs. JAMA 1996; 276:1473-1479.

10. Wolff JL, Starfield B, Anderson G: Prevalence, expenditures, and complications of multiple chronic conditions in the elderly. Arch Intern Med 2002; 162:2269-2276

11. Swami HM, Bhatia Vikas, Dutt Rekha, Bhatia SPS. A Community Based Study of the Morbidity Profile among the Elderlyin Chandigarh, India Bahrain Medical Bulletin.2002;24(1)

12. Ettinger WHJ, Fried LP, Harris T, Shemanski L, Schulz R, Robbins J. Self-reported causes of physical disability in older people: the Cardiovascular Health Study. CHS Collaborative Research Group J Am Geriatr Soc. 1994; 42:10351044

13. Rozzini R, Frisoni GB, Ferrucci L, Barbisoni P, Bertozzi B, Trabucchi M. The effect of chronic diseases on physical function. Comparison between activities of daily living scales \& the Physical Performance Test. Age Ageing.1997; 26:281-287

14. Boult C, Altmann M, Gilbertson D, Yu C, Kane RL. Decreasing disability in the 21 st century: the future effects of controlling six fatal and nonfatal conditions. Am J Public Health.1996; 86:13881393

15. Ihab Hajjar, Daniel T. Lackland, L. Adrienne Cupples, Lewis A. Lipsitz. Association Between Concurrent And Remote Blood Pressure And Disability In Older Adults. Hypertension. 2007;50:1026-1032

16. Hiremath Da, Hiremath D Lalita, Essentials Of Community Medicine-A Practical Approach. Jaypee Brothers, New Delhi. $1^{\text {st }}$ Edition 2004;13 